\title{
Time-resolved THz Laser spectra using a Fiber-interfaced Optical Heterodyne system
}

DOI:

10.1364/CLEO_SI.2015.STU4H.3

Link to publication record in Manchester Research Explorer

\section{Citation for published version (APA):}

Folland, T. G., Ramos-Pulido, A., Marshall, O. P., Beere, H. E., Ritchie, D. A., \& Chakraborty, S. (2015). Timeresolved THz Laser spectra using a Fiber-interfaced Optical Heterodyne system. In OSA Technical Digest (online) paper STu4H.3 Optical Society of America. https://doi.org/10.1364/CLEO_SI.2015.STu4H.3

\section{Published in:}

OSA Technical Digest (online) paper STu4H.3

\section{Citing this paper}

Please note that where the full-text provided on Manchester Research Explorer is the Author Accepted Manuscript or Proof version this may differ from the final Published version. If citing, it is advised that you check and use the publisher's definitive version.

\section{General rights}

Copyright and moral rights for the publications made accessible in the Research Explorer are retained by the authors and/or other copyright owners and it is a condition of accessing publications that users recognise and abide by the legal requirements associated with these rights.

\section{Takedown policy}

If you believe that this document breaches copyright please refer to the University of Manchester's Takedown Procedures [http://man.ac.uk/04Y6Bo] or contact uml.scholarlycommunications@manchester.ac.uk providing relevant details, so we can investigate your claim.

\section{OPEN ACCESS}




\title{
Time-resolved THz Laser spectra using a Fiber-interfaced Optical Heterodyne system
}

\author{
T. G. Folland ${ }^{1}$, A. Ramos-Pulido ${ }^{1}$, O. P. Marshall ${ }^{1,2}$, H. E. Beere ${ }^{3}$, D. A. Ritchie ${ }^{3}$ and S. Chakraborty ${ }^{1}$ \\ ${ }^{1}$ School of Electrical and Electronic Engineering, University of Manchester, Manchester, M13 9PL, UK. \\ ${ }^{2}$ School of Physics and Astronomy, University of Manchester, Manchester M13 9PL, UK. \\ ${ }^{3}$ Semiconductor Physics Group, Cavendish Laboratory, University of Cambridge, JJ Thomson Avenue, Cambridge, CB3 OHE, UK. \\ e-mail: s.chakraborty@manchester.ac.uk
}

\begin{abstract}
We report the first fully fiber-interfaced heterodyne system for time-resolved spectral characterization of $\mathrm{THz}$ quantum cascade lasers. By exploiting the bias probe rise time we study the current dependent mode tuning with 50ns temporal resolution.

OCIS codes: (250.0250) Optoelectronics; (140.5965) Semiconductor lasers, quantum cascade
\end{abstract}

\section{Introduction}

Time-resolved spectral investigation of THz Quantum Cascade Laser (QCL) emission is crucial for applications requiring high emission stability, such as coherent communications and spectroscopy. Earlier work has shown that it is possible to temporally resolve such spectral emission by heterodyning two THz QCLs on a whisker Schottky diode [1]. In this paper we up-convert THz signals to the near infrared (NIR) inside the QCL cavity [2] to demonstrate, to the best of our knowledge, the first fully optical fiber-interfaced communication system for the timeresolved heterodyne characterization of THz laser emission. The heterodyne waveform can be measured by oscilloscope and split into 50ns time frames, each containing spectral information about the emission of the QCL, which is extracted via a Fourier transform. By exploiting standard fiber optic communication technology, this system is more compact, cost-effective and-flexible than working directly in the THz, and could be used to demonstrate coherent on-chip signal processing and transmission via THz QCL.

\section{Device Fabrication, Characterization and Methods}

Terahertz QCLs based upon semi-insulating surface plasmon waveguides were fabricated from a $\mathrm{GaAs} / \mathrm{Al}_{0.15} \mathrm{Ga}_{0.85} \mathrm{As}$ wafer, using a bound to continuum active region with integrated NIR guide layer [2]. THz laser emission was first measured directly using a Bruker Vertex 80 FTIR. The THz QCL was biased using a pulse generator running at a variety of currents and repetition rates at $15 \mathrm{~K}$. This bias circuit provides a rise time delay of $\sim 700 \mathrm{~ns}$ measured at room temperature using a high speed current probe (see figure $2 \mathrm{a}$ ). The scheme used for generation of $\mathrm{THz}$ side modes and subsequent measurement of a radio-frequency (RF) beat note is illustrated in Figure 1a. First, NIR light from a tuneable $1.3 \mu \mathrm{m}$ external cavity laser was injected into the QCL waveguide via butt coupling single mode optical fiber to a QCL facet. The subsequent intracavity up-conversion of THz light to a telecoms side mode via nonlinear mixing with NIR light has been discussed in ref [2]. The generated THz side modes were collected from the other facet of the QCL using a second butt coupled single mode fiber, and measured using both a fast photodiode (Thorlabs DET08CFC/M) and an optical spectrum analyzer (Yokogawa AQ6370Z). To generate the heterodyne signal, light from a second $1.3 \mu \mathrm{m}$ external cavity laser was injected into the fiber via a coupler after the QCL. The generated RF beat was amplified using a $20 \mathrm{MHz}-3 \mathrm{GHz} 22 \mathrm{~dB}$ low noise amplifier (Minicircuits ZX60-3018G-S+), and then detected by a Keysight Infinium MSO9104A oscilloscope. A sample waveform of the RF beat note generated between the THz side mode and the second external cavity laser is shown in figure $1 \mathrm{~b}$, with the current pulse illustrated on the figure. This waveform was broken down into separate $50 \mathrm{~ns}$ frames, and a Fourier transform was performed frame by frame to analyze transient frequency variations in the RF beat note (figure 1c). The frequencies of both NIR lasers do not vary significantly over the time period of the pulse $(2 \mu \mathrm{s})$, so changes in beat note frequency can be attributed to the QCL emission.

\section{Results and Conclusions}

An indicative heterodyne measurement of QCL emission when driven by a $2 \mu$ s long current pulse is presented in figure $2 \mathrm{~b}$. After a short delay for the current to rise above threshold, lasing begins and there appears to be significant frequency tuning with a net tuning range of at least $1.7 \mathrm{GHz}$, after which the frequency stabilizes as the driving current reaches close to its maximum value. As expected, the timescale of this frequency tuning is comparable with that of the applied current pulse (figure 2a) passing through the QCL, suggesting that this tuning can be attributed to the shape of the current pulse. This transient frequency tuning $(>1.7 \mathrm{GHz})$ is similar to the current tuning measured 
via the FTIR (2.6GHz shown in figure 2c(i)). Current tuning is frequently attributed to Joule heating of the active region, as time resolved photoluminescence measurements of QCLs suggest that the active region temperature may increase by as much as $10 \mathrm{~K}$ across pulses of the order of $2 \mu \mathrm{s}$ long [4]. However, characterization of the QCL emission by FTIR (figure 2(c)(ii)) shows that only $1.2 \mathrm{GHz}$ of frequency tuning could be achieved using as much as $40 \mathrm{~K}$ variation in laser temperature. This suggests that the $>1.7 \mathrm{GHz}$ transient tuning cannot be attributed to Joule heating. We can instead attribute this current tuning to the gain properties of the active region [3]. Inter-subband transitions are intrinsically fast, any variations in driving current will rapidly change the gain shape of the QCL. Variations in this effective gain profile will alter the modal mode pulling and lead to rapid frequency tuning, as observed in this experiment.

In conclusion, we have developed the first fully optical fiber compatible heterodyne technique for the timeresolved measurement of THz QCL emission. This system could be used for coherent communication experiments using THz QCLs. We observe that when a THz QCL is operated with non-ideal current pulses there is significant modal tuning, attributed to variations in the gain profile with driving current. This work was partly supported by EPSRC NOWNANO funding. The authors would like to thank Dr. D. Heard (Yenista Optics) for loan of a 1.3 $\mu \mathrm{m}$ laser.
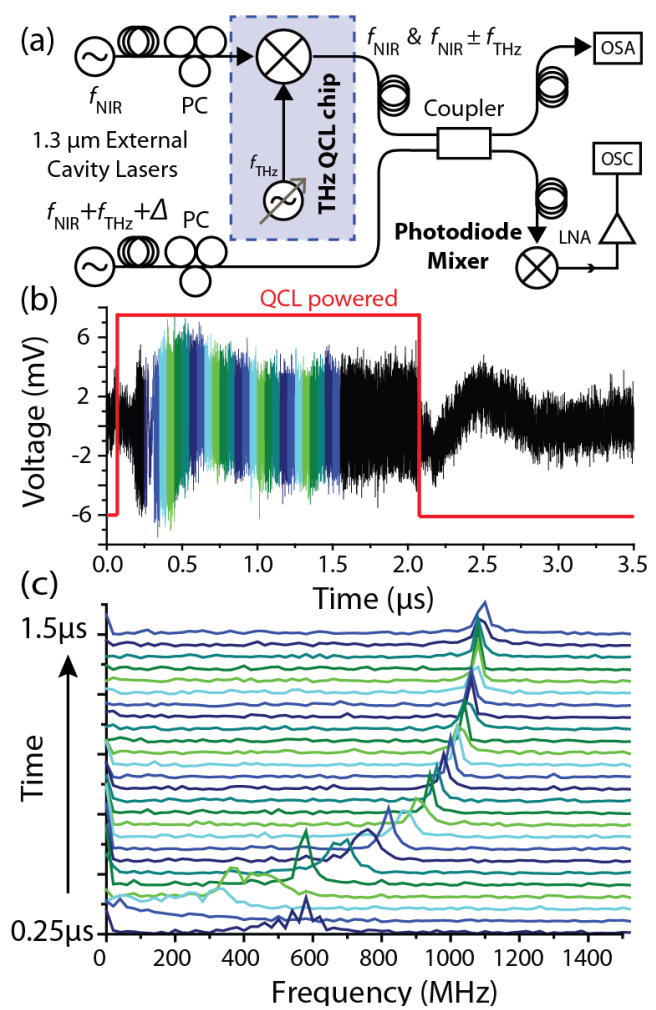

Figure 1. (a) is a schematic representation of our beat note detection setup (b) shows a sample waveform of the electrical beat note generated by our heterodyne system. By splitting the waveform into 50ns windows and performing the Fourier transform (c) we can track the frequency of the generated RF with $20 \mathrm{MHz}$ resolution.
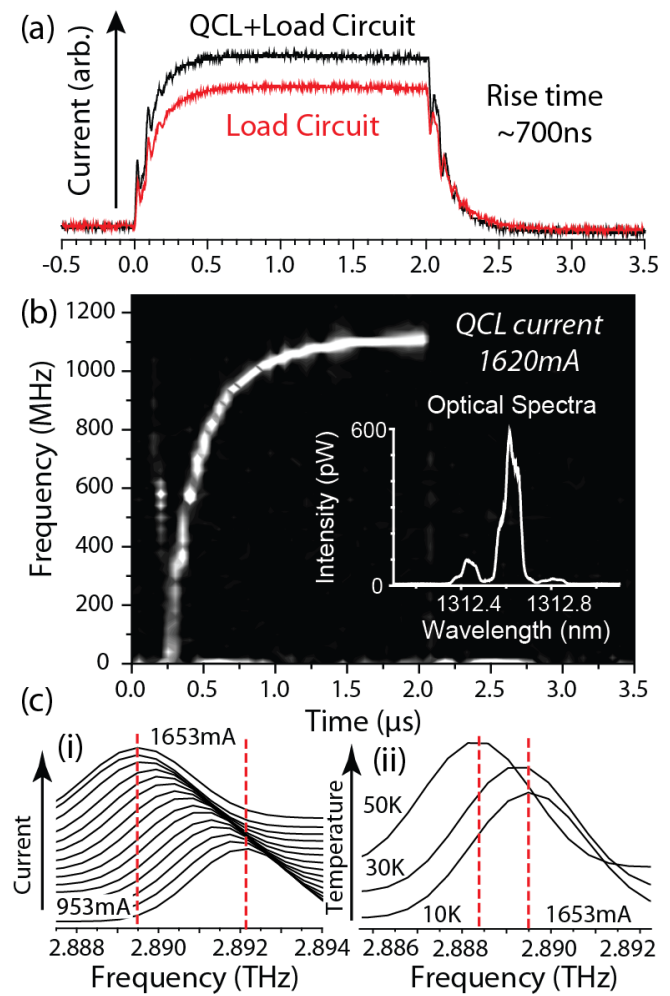

Figure 2. (a) shows an illustrative current pulse applied to the QCL at $100 \mathrm{kHz}$ with a $20 \%$ duty cycle. (b) shows the frequency of the beat note as a function of time, where the BN passes through DC at 250ns. (c) shows fine tuning in the QCL with both (i) current, and (ii) temperature.

\section{References}

[1] J. M. Hensley, J. Montoya, M. G. Allen, J. Xu, L. Mahler, A. Tredicucci, H. E. Beere, and D. A. Ritchie, "Spectral behavior of a terahertz quantum-cascade laser.," Opt. Express, vol. 17, no. 22, pp. 20476-83, Oct. 2009.

[2] S. S. Dhillon, C. Sirtori, J. Alton, S. Barbieri, A. de Rossi, H. E. Beere, and D. A. Ritchie, "Terahertz transfer onto a telecom optical carrier," Nat. Photonics, vol. 1, no. 7, pp. 411-415, Jul. 2007.

[3] O. P. Marshall, M. Khairuzzaman, H. E. Beere, D. A. Ritchie, and S. Chakraborty, "Broadband photonic control for dual-mode terahertz laser emission," Appl. Phys. Lett., vol. 102, no. 18, p. 181106, 2013.

[4] M. S. Vitiello, G. Scamarcio, and V. Spagnolo, "Time-resolved measurement of the local lattice temperature in terahertz quantum cascade lasers," Appl. Phys. Lett., vol. 92, no. 10, p. 101116, Mar. 2008. 